DOI: 10.12731/2227-930X-2016-2-123-136

\title{
CONCEPTUAL MODEL OF INFORMATION SYSTEM OF THE AGRICULTURAL ENTERPRISES
}

\section{Uladzimir Buts, Zhang Tszindong}

Abstract. Research subject represented by the theoretical and practical issues use of information resources in the agricultural business.

Research aim is to formation of a conceptual model of information system of agricultural enterprises according to the requirements of sustainable development.

Research methods. The work is prepared on basis of several scientific methods and approaches including monographic, analytical, computational and constructive methods of mathematical and structural logic simulation of information systems.

Research results. Based on the assessment of the results of research information systems in agribusiness, as reflected in the theoretical review, the author designed principles of the information system for the agricultural enterprise for sustainable development of agribusiness.

Sphere of application of the research results. State and regional authorities of economic regulation. Agricultural enterprises and farmers.

Keywords: agricultural enterprise; information system; sustainability agricultural production; software.

\section{Relevance of the problem}

Strong recovery of China's economy, a substantial increase in the gross domestic product (GDP), while the economic development of China's agriculture is relatively slow, China's agricultural economy in the proportion of the total GDP is declining. How to accelerate the development of agricultural economy, enhance the effective utilization of agricultural information resources, active modernization of China's 
agricultural become the point of China's Computerization construction. China's agricultural Computerization construction and development of agricultural economics is to develop and the use of agricultural information resources for the core, to promote the government agricultural departments', agribusiness' and farmers' use of information technology, to promote agricultural production Computerization, agricultural operation Computerization, agricultural management Computerization, agricultural services Computerization for the goal. At present China's rapid agricultural development of information resources use and develop, also has a certain foundation scale, but equally highlight many problems:

- Such as category of agricultural information resources is complex, classification is not clear;

- The low-quality agricultural information resources, poor timeliness, inefficient use; feeding and receiving of agricultural information resources appear interruption;

- The Farmers insufficient attention to agricultural information resources lead to cuts and reduction;

- The enterprises have no enthusiasm to develop agricultural information resources due to the weak of IP-building.

This paper through studies the Utilization efficiency of agricultural information resources affect the economy of agriculture by TAM/TTF integration model ,to explore the importance of agricultural information resources and the role of agriculture information resources in agriculture economic aspects.

\subsection{Problem investigation degree}

Increased activity of scientific research application of information systems in the economy connected with the beginning of the XX century. In the world of economic thought special attention paid to these problems neoclassical and neoinstitutionalists. Notable researchers use information systems in the economy and society should be mentioned, such as Ch. Babbage, F. Hayek, F. Knight, K. Boulding, J. Sti- 
gler, J. Stiglitz, D. Akerlof, R. Coase, K. Arrow , D. North, M. Spence, F. Machlup, T. Umesao, I. Masuda, M. McLuhan [1, 2]. As result of their studies formed the economic theory of information. In a study of the impact of information and information technologies in the development of production, special attention should be working T. Sakayi, T. Stewart, P. Pilzer, L. Edvinsson, M. Malone, E. Weizsacker [3, 4]. The study of the practical aspects of the use of various information technologies in the management of enterprises engaged P. Drucker, P. Strassman, D. Trout, S. Bir, R. Ackoff, Y. Malhotra, T. Davenport, B. Goldstein, G. Poppel, L. Prusak, B. Lev, M. Earl [5, 6, 7].

\subsection{Problem statement}

Agricultural information resources can divided into two categories: one for the traditional use of natural resources for agricultural production; the second comprises the features of modern agricultural production, which characterizes it as a socio-economic information. Among the first category of information, information on natural resources, including climate, information on soils, water resources, the growth of crops, pest and diseases, natural disasters. Among the social and economic encouraged provide information on the functioning of agricultural markets, legal and administrative, achievements of agricultural science and education. Information on the use of natural resources is a fundamental part of agricultural information resources, independent of traditional agricultural production and use of long-term information, is the modernization of the basic information needed for agricultural production. Socio-economic information differs from the information for the traditional agricultural tools to improve production efficiency and improving its structure.

\section{Model and methods}

Now agricultural information Resources seemingly larger volume and variety, it is important that agricultural producers in the utilization of agricultural information resources. On China's utilization of agri- 
cultural information resources evaluation methods, the paper selected TAM / TTF integrated model, the use of the complementarity between TAM model and the TTF model, the formation of a complete evaluation of the utilization of agricultural information resources (see Figure 1).

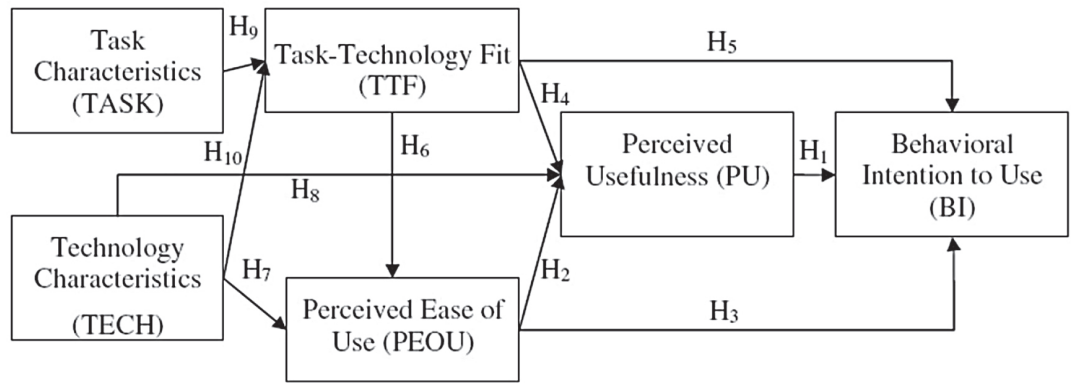

Figure 1. Integrated theoretical model of TTF and TAM [8-12]

TAM model. In 1986, Fred Davis rational behavior based on the theory proposed technology acceptance model in his doctoral thesis, tried to explain the reasons affect the user to accept or reject an information technology [8]. This model is constantly being tested and expanded, and is proven to be successfully used in a large number of prediction, interpretation and evaluation information system analysis. TAM believe the intent usability and usefulness of intent are two key factors affecting the use of information resources system, external variables indirectly affect attitudes and behavior intended use and, ultimately, used to establish the model in Davis and other researchers to technology acceptance model-based model for the expansion of established, there are 10 pairs of relations:

1) eases of intent - intent usefulness,

2) Use of fullness of intent - use attitudes,

3) Eases of intent - use attitudes,

4) Attitude - Behavior intent,

5) Usability - behavioral intention,

6) Usefulness - behavioral intention, 
7) Attitude - end use,

8) Behavioral intentions - end use,

9) Ease - end use,

10) Usefulness - end use.

TAM model established from the user to explore the attitudes and behavior information resource system usage, but there is no information technology for its own internal factors, it is not conducive to the quality of the IT itself on the use of information resources systems analysis and interpretation.

TTF model. Goodhue and Thompson (1995) believe that the model was use to study information systems such as TAM [9]. TRA is mainly targeted users of the information system by the attitude and behavior of the final effect of the use of the model, without considering the actual use (Users and Technology) and adaptation of tasks and technology between the Tasks of technical adaptation therefore proposed model. TTF considered a match between information technology and it needs to complete the task can be a good evaluation and interpretation of the information system. TTF model has four main factors: The first is the task characteristics and technical features, which together affect the task of technical adaptation, technology adaptation and task forces ultimately affect the final intended use and actual use [10].

TAM/TTF Integration Model. Dishaw and Strong (1999) first time TAM model and combine to form TTF model TAM / TTF integration model for interpretation and evaluation of information systems [11]. TAM model will focus on users and the lack of IT itself TTF model. Features and you need to focus on information technology and adaptation between tasks characteristic integrate the use of user behavior and mentality, through the internal factors (functional information system technology to affect the user behavior) as well as external factors (user behavior affect the user's cognitive information systems) both more complete interpretation and evaluation of information systems. There for this paper TAM / TTF integrated model for the utilization of agricultural informa- 
tion resources in China to study the function of internal factors from both agricultural information resources people use behavior affecting. Agricultural information resources for agricultural producers and agricultural producers from both external factors awareness of the usefulness of agricultural information resources and ease China cognitive research utilization of agricultural information resources both to further explore the relationship between China and the utilization of agricultural information resources in agriculture between China's economic production [12].

\section{Results}

Information technology and systems that enhance the quality of information to ensure the economic stability of the enterprises are encouraged to consider by economic sustainability.

Organizational stability characterizes the stability of the internal organizational structure (Company structure and relationships of its main divisions) and established and operational links between the Departments, the efficiency of joint work depends on the regularity of procedures and processes paperwork. Our studies show that $75 \%$ of staff time utilized on training, maintenance, filling up, search and transmission of various documents. It consequently the introduction of electronic document management system, which is a set of software and hardware, providing the automation of work with documents throughout their life cycle and processes of information interaction of employees across the enterprise.

Today the market offers information services systems such as the “platform for managing business processes and documents DocsVision» (Company «DocsVision»); "Document Management: software LanDocs» (LANIT group); "BUSINESS" (company "Electronic Office Systems"); "The system of electronic document management and office automation" Euphrates-Document Management "(Company Cognitive Technologies);

Since 2001, the increasing popularity began to gain the concept of "enterprise content management (Enterprise Content Management ECM) ». ECM-system - the system of enterprise content management, 
which developed for storing and processing unstructured data (text documents, images, spreadsheets, etc.). Common data applications ECM-system allows to not only create and access them from different sources and easily manipulate them. The main objective of ECM-systems - to ensure efficient management of the accumulated information assets of the enterprise in order to increase productivity and ensure the company's sustainable competitive advantage.

The level of technical stability of agricultural enterprises in the contemporary economy largely depends on the technical base of the company, corresponding to modern requirements of scientific and technological progress. Modern agricultural machines presented on the market diverse range of brands and models. Of particular interest are the machine tools based electronics and information technology, the use of which is aimed at improving the quality and quantity of output, fuel economy, as well as to improve the comfort of work, management techniques and monitoring of technological operations. As a result, documentation of production processes and product quality indicators of farm managers receive quality information for production management.

For example, the system CLAAS TELEMATICS allows you to get information from the combine. With it you can diagnose the car, find out what the performance, whether all adjustments, which employs processor, whether the fuel is used efficiently, etc. The system can be installed on all harvesters CLAAS. Information System AFIS Agrotron company DEUTZ-FAHR includes a terminal display and service through which you can manage all hinged instruments with the appropriate equipment.

Solutions using GPS systems enable us to satisfy the requirements of precision farming. These systems help the driver to precisely the band when working with tools with a large width, regardless of the time of day and weather conditions. The navigation system works with an accuracy of a few centimeters, allowing better use of working width and achieve higher performance. In addition, fuel economy, which is especially important in light of the highenergy prices. 
Production stability characterized by the ability of the enterprise to achieve planned business results through effective use of available resources.

Animal of the XXI century is inconceivable without electronic control systems herd - automated system that allows you to keep all the data on the status of the animal in a computer database. Because of this, all the information about diseases, pregnancy, and must always be available to those skilled in the farm. Electronic control systems make it possible to keep track of virtually all parameters of heredity in the herd. Daily information on technical and veterinary data, allows you to organize the work of specialist dairy farm based on reliable information, fully control the situation on the dairy farm, to take timely managerial decisions and develop a plan of action.

Examples can serve as a system of farm management DelPro TM (company DeLaval) for farms with a stanchion, herd management system ALPRO TM (company DeLaval), computerized farm management company SAEAFIKIM and others. The software package FARM software company Agrovision, is the most common software product Management for pig farms in Russia (more than 40 pig farms) and in most European countries. FARM software is a versatile software product that allows real-time to keep records of livestock farming, to analyze the situation in the economy and generate reports on the movement of livestock, for reproduction, fattening, calculation of cost, etc.

Social sustainability. The successful development of the agricultural enterprise depends largely on the personnel of the enterprise, its qualifications, ability and desire to work productively. Therefore, one of the key places in the overall strategy of the company is addressing the issue of effective human resource management. Over the last decade, the complexity of the problem of human resource management in diversified businesses increased significantly. This is due to the continued expansion of the functions assigned to personnel services, increasing the degree of diversity of information that must be processed, 
or at least take into account, in personnel services, constant changes in the requirements as to the contents of this information and its presentation in various instances.

Today the market of information technologies can offer a range of full-featured system for personnel management is not inferior to Western counterparts either in functional or in technological capabilities. These systems allow you to perform tasks such:

Management structure and staffing of the enterprise; personnel Management; maintenance of personnel records; time management; timecard management; calculation and payroll, bonuses, taxes, single social tax; the administrative workflow management personnel and accounting work, certification and identification of needs (education, training) employees;

Formation of statistics, forms, and a variety of reports for internal and external use.

Examples of systems for personnel management can serve as a "system of Alfa / Personnel Management" (company "Informkontakt"); automated personnel management system BOSS-Personnel (Company "boss. HR Systems"), the contour of "Human Resources" (Corporation "Galaxy"), "1C: Salary and Personnel Management 8" (1C). An interesting development represented by 1C. "1C: Enterprise 8. Evaluation of staff" is a complete solution for automation of processes of personnel evaluation and design teams or teams on the basis of psycho-diagnostic test that allows you to automate testing during recruitment, appraisal, and to plan and monitor the development of the employees.

Environmental sustainability. In the second half of the twentieth century was the most pressing problem of reduction in crop production content of vitamins and minerals and accumulation products, both crop and livestock production of harmful substances (nitrates, pesticides, hormones, antibiotics, and so on. N.). the Reason - the degradation of soils. Unfortunately, in time the problem is not completely solved, nevertheless, it may be noted many positive achievements. An example is the GIS products, GIS technology, GIS services, which described above. 
The functionality of the program "AdeptIS: Master planning in agriculture Version 3" for the 1C: Enterprise 8.0 include the ability to input the results of soil analysis (based on the chemical content), whereby using classifiers formed registers of land use and is determined by the need for fertilizer for each field. Results of analyzes of soil visual (color) are presented in the fields of electronic maps. There is also a possibility of optimal (cost) selection of fertilizers, providing the identified need for macronutrients.

Financial stability. The current stage of economic development characterized by an increase in volume of information resources, not in production only, investment, marketing activity, primarily in the financial activity of the enterprises. Efficiency and adequacy of the information display of financial transactions, the possibility of their accounting and analysis, prediction and control to extent depend on the implementation of the management of financial flows of modern information technologies. A significant role in the process of enterprise management plays accounting, where about $60 \%$ of all information. Computer accounting software market in Russia is represented by a wide range of options - from the most simple to branched, carrying out a wide range of operations with deep intelligence, "1C: Enterprise 8. Accounting agricultural enterprise" (the company " $1 \mathrm{C}$ " and the company "AgroSoft"); "1C: Enterprise 8. Accounting poultry farm" ("1C" and "1C-Rarus" and "1C-Rarus NN"); "AdeptIS Accounting and records of agricultural organizations" (ZAO AdeptIS); Info-Accountant 10 (the company "INFO") and others.

Marketing stability. The term CRM (Customer relationship management - Customer Relationship Management) designate, as a rule, not only information systems containing functions of customer relationship management, but also the very strategy of customer orientation, the essence of which - to combine different sources of information about customers, sales, responses on marketing activities, market trends, for the most close relations with customers.

Usually CRM-solution includes support for managing sales, marketing and customer service. Examples of these solutions are: 
CRM-system "Marketing and Management" ("Compass"); CRMsystem "Sail" ("Corporation SAIL"); 1C: Enterprise 8. CRM TRAC (joint solution "1C" and "1C-Rarus").

Improve the economic stability of the whole will promote the use of corporate information systems, whose main task is to automate all functions from enterprise management business planning to analyze the results of the company. In larger enterprises it is expedient to implement information systems class ERP, for example, "Galaxy ERP» (corporation “Galaxy»), Microsoft Dynamics AX (Corporation Microsoft), IT-company (Corporation "Information Technology"), and others. Corporate information systems are complex, expensive and require customization.

The market information systems presented as complex information systems, which do not belong to the class of ERP systems, but aimed at the implementation of the set of management tasks. Examples include:

"1C: Enterprise 8. Management of agricultural enterprise" (the company "1C" and the company "INTECO Black Earth"); "AdeptIS: Agricultural complex" system "1C: Enterprise 8" (ZAO AdeptIS); the Software product "Sail-agriculture" ("Corporation SAIL"), and others.

Most enterprises implemented several information systems, such as electronic document management system, the system of personnel management, accounting package, CRM-system. In this case, it is necessary to solve the problem of the data consolidation, so it is necessary to choose a system compatible with each other, having the possibility to work with a common database.

\section{Discussions}

Revealed the following problems of the use of agricultural information resources of China and the Republic of Belarus:

1) The deficit of the market and scientific and technical information;

2) Information flows not aimed at the maintenance of the rural population;

3) The backlog of information technology on modern requirements for the construction of information systems; 
4) Lack of close international exchanges between China and Belarus in the field of information systems in agriculture.

It proposed to allocate the following basic directions of information flows within the information system of agricultural enterprises:

Definition of the market status of the enterprise (organization);

Determination of the objectives and strategies of its activities;

Decision of tools and instruments of the strategy.

Modern conditions of production in agricultural enterprises require a large amount of information resources. The most important components of a socio-economic information based on accounting data. For the purposes of strategic planning, economic analysis and monitoring proposed to divide flows of socio-economic information on the areas of accounting:

Administrative,

Financial,

Tax.

According to the established concept of the agricultural information system of the enterprise, information, aggregated by fields of accounting, management transferred to the enterprise, which decides:

Volume and product mix;

Purchase of material and technical resources;

Sale of finished products;

Introduction of innovative technologies.

Expected results from the implementation of a new information system of strategic management:

Optimization the relationship between the units;

Streamlining electronic document;

Increase staff motivation;

Achieving positive financial results of the company.

\section{Conclusions}

Scientific article for authors highlighted the problem of the use of information resources in agribusiness (in the context of improving the sustainability of agricultural production): 
Existing information systems do not provide the stability of the complex, and affect only certain types of sustainability,

Existing diversity of software products requires adaptation to each other in terms of information exchange and sharing.

During for new approaches to these problems, the author a conceptual model of information system of the agricultural enterprises. The essence of the conceptual model is that it integrates the methodological principles of the agricultural information system of the enterprise. The effectiveness of the model tested on the example of the functioning of the agricultural enterprises of the Republic of Belarus and the People's Republic of China.

\section{References}

1. First published in Green, C.D., Shore, M., \& Teo, T. (Eds.) (2001). The Transformation of Psychology: Influences of 19th-Century Philosophy, Technology, and Natural Science (pp. 133-152). Washington, DC: American Psychological Association.

2. Friedman J. (2005) Popper, Weber and Hayek the epistemology and politics of ignorance. Critical Review 17, nos.1-2 ISSN 0891-3811. www.criticalreview.com

3. Sakai T. Riemannian Geometry. Translations of Math. Monographs, vol. 149, Amer. Math. Soc., Providence, RI, 1995, xiv+358 pp., ISBN 0-8218-0284-4.

4. von Weizsäcker E., Hargroves K., Smith, M. Desha, C. and Stasinopoulos P. (2009). Factor 5: Transforming the Global Economy through $80 \%$ Increase in Resource Productivity. Earthscan, UK and Droemer, Germany. ISBN 978-1-84407-591-1.

5. Peter F. Drucker (2005) The Five Deadly Business Sins. This series of articles on the work of Peter F. Drucker. The Wall Street Journal, online edition, December 27, 2005. www.lib.uwo.ca/business/dru.html

6. Pisello T., Strassmann P. (2003) IT Value Chain Management - Maximizing the ROI from IT Investments. Information Economics Press. www.strassmann.com 
7. Trout J.D. (2009) The Empathy Gap: Building Bridges to the Good Life and the Good Society. Viking/Penguin, New York, February 2009. ISBN 0-670-02044-3.

8. Davis F.D., and Warshaw P.R. (1992) Extrinsic and Intrinsic Motivation to Use Computers in the Workplace. Journal of Applied Social Psychology (22:14), pp. 1111-1132.

9. Goodhue, Dale L; Thompson, Ronald L (1995) Task-technology fit and individual performance. MIS Quarterly; Jun 1995; 19, 2; ABI/INFORM Global pg. 213.

10. Gebauer J., Michael J. Shaw, Michele L.G. (2010) Task-technology fit for mobile information systems. Journal of Information Technology 25, 259-272 (September 2010) | doi:10.1057/jit.2010.10.

11. Mark T. Dishaw, Diane M. Strong, D. Brent Bandy (2002) Extending the task-technology fit model with self-efficacy constructs. Eighth Americas Conference on Information Systems, pp. 10211027.

12. Samia Al-Mehmadi (2012) TTF and TAM in Online Shopping: An Integrated Model. Developmental (Discussion) Paper. International Journal of Management and Marketing Academy, Vol. 1, No. 2, pp. 106-125.

\section{DATA ABOUT THE AUTHORS}

Uladzimir Buts, Candidate of Economic Sciences, Associate Professor of the Economic Faculty

Belarusian State Agricultural Academy

5, Michurina Str., Gorki, Mogilev region, 213407, Belarus butz_wladimir@hotmail.com

Zhang Tszindong, Master Student of the Economic Faculty Belarusian State Agricultural Academy 5, Michurina Str., Gorki, Mogilev region, 213407, Belarus kingdomzhang118@gmail.com 